OAK RIDGE

NATIONAL LABORATORY

ORNL/TM-2012/90

MANAGED BY UT-BATTELLE

FOR THE DEPARTMENT OF ENERGY

\title{
Greenhouse Gas Emissions from U.S. Hydropower Reservoirs: FY2011 Annual Progress Report
}

Arthur Stewart

Jennifer Mosher

Patrick Mulholland

Allison Fortner

Jana Phillips

Mark Bevelhimer

September 2011

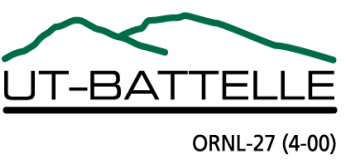




\section{DOCUMENT AVAILABILITY}

Reports produced after January 1, 1996, are generally available free via the U.S. Department of Energy (DOE) Information Bridge.

Web site http://www.osti.gov/bridge

Reports produced before January 1, 1996, may be purchased by members of the public from the following source.

National Technical Information Service

5285 Port Royal Road

Springfield, VA 22161

Telephone 703-605-6000 (1-800-553-6847)

TDD 703-487-4639

Fax 703-605-6900

E-mail info@ntis.fedworld.gov

Web site http://www.ntis.gov/support/ordernowabout.htm

Reports are available to DOE employees, DOE contractors, Energy Technology Data Exchange (ETDE) representatives, and International Nuclear Information System (INIS)

representatives from the following source.

Office of Scientific and Technical Information

P.O. Box 62

Oak Ridge, TN 37831

Telephone 865-576-8401

Fax 865-576-5728

E-mail reports@adonis.osti.gov

Web site http://www.osti.gov/contact.html

This report was prepared as an account of work sponsored by an agency of the United States Government. Neither the United States Government nor any agency thereof, nor any of their employees, makes any warranty, express or implied, or assumes any legal liability or responsibility for the accuracy, completeness, or usefulness of any information, apparatus, product, or process disclosed, or represents that its use would not infringe privately owned rights. Reference herein to any specific commercial product, process, or service by trade name, trademark, manufacturer, or otherwise, does not necessarily constitute or imply its endorsement, recommendation, or favoring by the United States Government or any agency thereof. The views and opinions of authors expressed herein do not necessarily state or reflect those of the United States Government or any agency thereof. 


\title{
Greenhouse Gas Emissions from U.S. Hydropower Reservoirs: FY2011 Annual Progress Report
}

\author{
Arthur Stewart \\ Jennifer Mosher \\ Patrick Mulholland \\ Allison Fortner \\ Jana Phillips \\ Mark Bevelhimer
}

September 2011

\author{
Prepared for: \\ Wind and Water Power Technologies Program \\ Office of Energy Efficiency and Renewable Energy \\ U.S. Department of Energy \\ Washington, D.C. \\ Prepared by: \\ Environmental Sciences Division \\ Oak Ridge National Laboratory \\ P.O. Box 2008, Oak Ridge, TN 37831 \\ managed by \\ UT-Battelle, LLC \\ for the \\ U.S. Department of Energy \\ under Contract No. DE-AC05-00OR22725
}


[THIS PAGE LEFT BLANK INTENTIONALLY] 


\section{CONTENTS}

Page

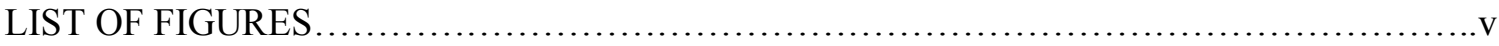

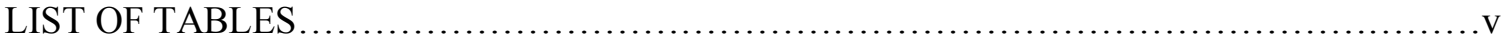

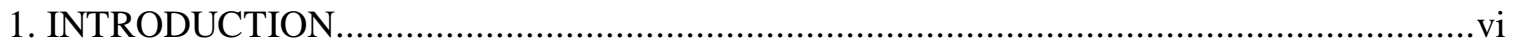

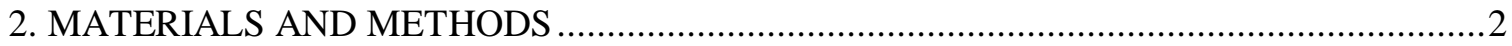

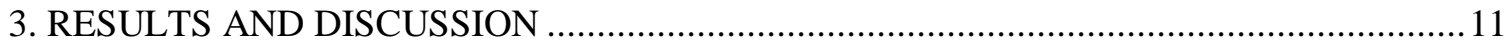

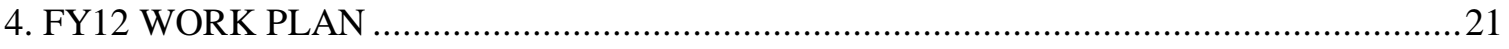

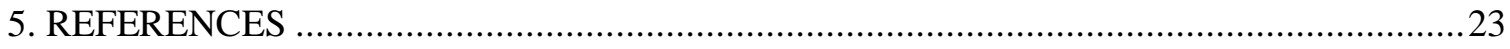


[THIS PAGE LEFT BLANK INTENTIONALLY] 


\section{LIST OF FIGURES}

Page

Fig. 1. Map of Douglas Reservoir in Eastern Tennessee.....................................

Fig. 2. Photograph of Douglas Reservoir taken from the forebay area of the reservoir............4

Fig. 3. F-ratios plotted for increasing temperatures and $\mathrm{CH}_{4}$ emission rates in Douglas Lake....14

Fig. 4. Mean diffusive emissions ( $\pm \mathrm{SE}$ ) of $\mathrm{CO}_{2}$ (upper) and $\mathrm{CH}_{4}$ (lower) from Douglas Lake...15

Fig. 5a. Monthly estimations of $\mathrm{CO}_{2}$ emissions from the surface of Douglas Reservoir..........17

Fig. 5b. Monthly estimations of $\mathrm{CH}_{4}$ emissions from the surface of Douglas Reservoir..........17

Fig. 6. Allatoona Dam and Reservoir located in northern Georgia, operated by USACE.........18

Fig. 7. Cherokee Dam and reservoir located in Eastern Tennessee, operated by TVA............18

Fig. 8. Watts Bar forebay and dam, located in Eastern Tennessee........................... 19

\section{LIST OF TABLES}

Table 1. Net diffusive emissions of $\mathrm{CO}_{2}$ and $\mathrm{CH}_{4}$ from Douglas Lake and its tailwaters, and from the free-flowing French Broad River.

Table 2. Measured parameters for 5 main channel and 5 coves sites in Douglas

Reservoir.....

Table 3. Results of two-way ANOVAs for effects of site depth (shallow versus deep) and surface water temperature (cool versus warm) on the diffusive emissions of $\mathrm{CO}_{2}$

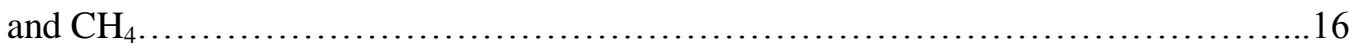


[THIS PAGE LEFT BLANK INTENTIONALLY] 


\section{INTRODUCTION}

The primary objective of this study is to quantify the net emissions of key greenhouse gases (GHG) - notably, $\mathrm{CO}_{2}$ and $\mathrm{CH}_{4}$ - from hydropower reservoirs in moist temperate areas within the U.S. The rationale for this objective is straightforward: if net emissions of GHG can be determined, it would be possible to directly compare hydropower to other power-producing methods on a carbon-emissions basis.

Studies of GHG emissions from hydropower reservoirs elsewhere suggest that net emissions can be moderately high in tropical areas. In such areas, warm temperatures and relatively high supply rates of labile organic matter can encourage high rates of decomposition, which (depending upon local conditions) can result in elevated releases of $\mathrm{CO}_{2}$ and $\mathrm{CH}_{4} \cdot \mathrm{CO}_{2}$ and $\mathrm{CH}_{4}$ emissions also tend to be higher for younger reservoirs than for older reservoirs, because vegetation and labile soil organic matter that is inundated when a reservoir is created can continue to decompose for several years (Galy-Lacaux et al. 1997, Barros et al. 2011). Water bodies located in climatically cooler areas, such as in boreal forests, could be expected to have lower net emissions of $\mathrm{CO}_{2}$ and $\mathrm{CH}_{4}$ because their organic carbon supplies tend to be relatively recalcitrant to microbial action and because cooler water temperatures are less conducive to decomposition. 
[THIS PAGE LEFT BLANK INTENTIONALLY] 


\section{MATERIALS AND METHODS}

As noted in last year's annual progress report (ORNL/TM-2012/91), we initially selected Douglas Lake, a TVA-operated hydropower reservoir located near Dandridge, Tennessee, to begin our studies. Douglas Lake was created in 1943 by damming the French Broad River. The reservoir is centered near Dandridge, Tennessee (N $\left.36^{\circ} 00^{\prime} 55.1^{\prime \prime}, \mathrm{W} 83^{\circ} 24^{\prime} 51.2^{\prime \prime}\right)$, about $46 \mathrm{~km}$ east of Knoxville, Tennessee (Figure 1). The dam is a reinforced concrete gravity-type dam $520 \mathrm{~m}$ long and $62 \mathrm{~m}$ high. The reservoir has four power-producing units with a total capacity of $165 \mathrm{MW}$, a flood-storage capacity of $1.33 \times 10^{9} \mathrm{~m}^{3}$, and a surface area of about $120 \mathrm{~km}^{2}$; it has about $885 \mathrm{~km}$ of shoreline, and is used extensively for recreational boating and sport fishing (www.tva.gov/sites/douglas.htm). Annually, elevation of the water surface varies by about 13.4 meters. The reservoir rated "low fair" by Tennessee Valley Authority (TVA) with respect to overall ecological health in 2009; dissolved oxygen concentrations at forebay and mid-reservoir sites tend to be very low during the summer, especially in the lower half of the water column.

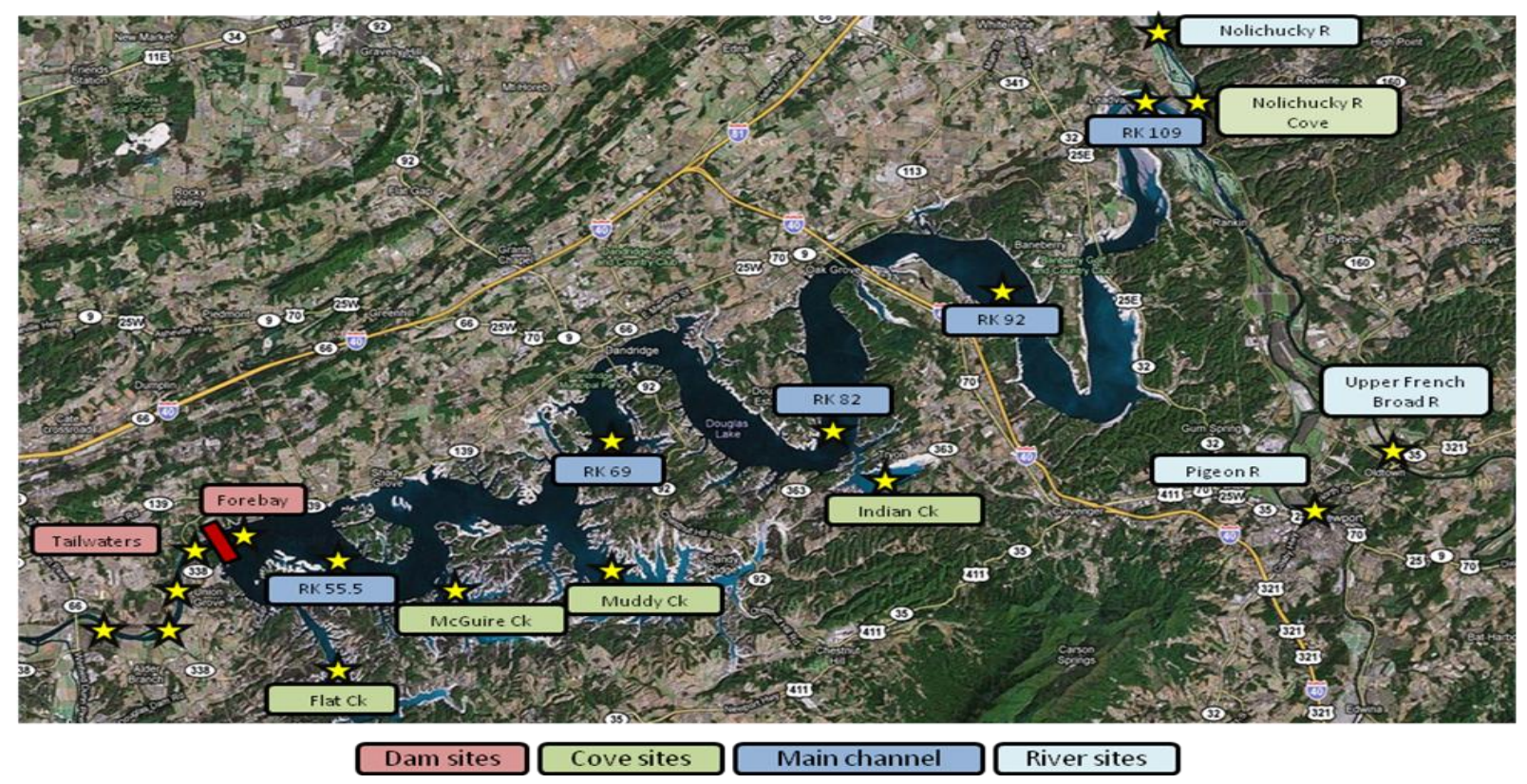

Figure 1: Map of Douglas Reservoir in Eastern Tennessee. Red squares depict forebay and tailwater sampling sites. Green squares indicate cove sites, Blue squares indicate main channel sites and gray squares depict free-flowing river sites.

In last year's annual progress report, we summarized results for the first five months of sampling of Douglas Lake (March through July, 2010). In the current report, we provide a summary of findings for Douglas Reservoir, based on 10 sampling campaigns total, from January through November, 2010. We then describe several other project accomplishments, and then report our progress on three additional hydropower reservoirs (Allatoona Lake, in northern Georgia; 
Cherokee and Watts Bar reservoirs, in Tennessee) that have been sampled on multiple occasions in FY11.

\section{Sampling dates and locations}

Sampling of Douglas Lake commenced in January, 2010, and starting in mid-March, continued on a monthly schedule through mid-November, 2010 (ten sampling dates). Included as sampling sites were 10 reservoir locations (five main channel sites and five cove sites), three major tributary river sites, a forebay site, and four tailwater sites (Figure 1).

The main channel sites were RK (river kilometer) 55.5, RK 69, RK 82, RK 92 and RK 109; the five cove sites were MacGuire Creek, Mc; Flat Creek, FC; Indian Creek, IC; Muddy Creek, Mud; and Nolichucky Cove, NC. The forebay site (FB) was immediately upstream of the dam, and one tailwater site (tailwater 1) was immediately downstream of the dam. Three additional tailwater sites (T2, T3 and T4) were at increasing distances, extending $6.44 \mathrm{~km}$ from the dam. The three free-flowing major tributary river sites upstream of the reservoir were the Upper French Broad River (FBR); the Pigeon River (PR); and the Nolichucky River (NR) (Figure 1).

On each sampling date, we measured $\mathrm{CO}_{2}$ and $\mathrm{CH}_{4}$ emissions and key water-quality factors so as to permit opportunity for statistically identifying factors that controlled or influenced the rates of greenhouse gas (GHG) emissions, seasonally and spatially.

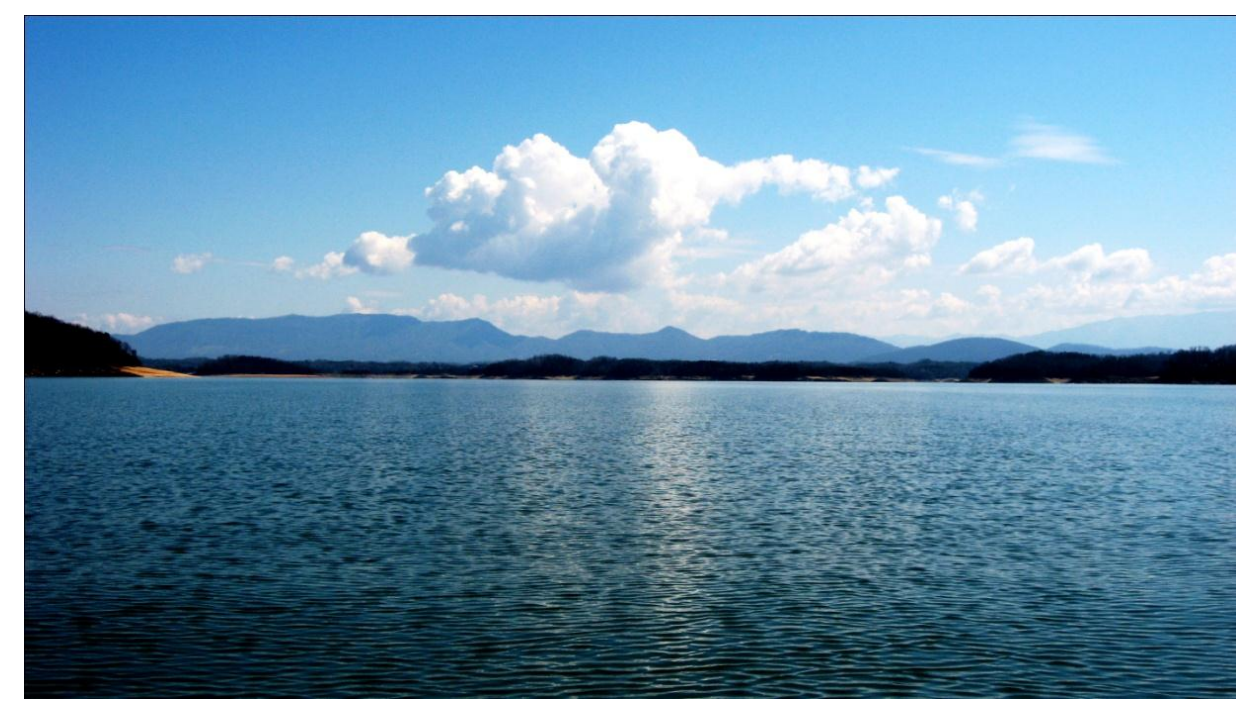

Figure 2: Photograph of Douglas Reservoir taken from the forebay area of the reservoir.

\section{Diffusive emissions of $\mathrm{CO}_{2}$ and $\mathrm{CH}_{4}$}

\section{Floating chamber measurements}

Diffusive fluxes of $\mathrm{CO}_{2}$ and $\mathrm{CH}_{4}$ from the reservoir surface were made at five main channel sites and five cove sites that were representative of reservoir morphometry. These fluxes were 
determined using a floating chamber (volume, $19.8 \mathrm{~L}$; surface area, $0.2 \mathrm{~m}^{2}$ ) with sidewalls extending about $5 \mathrm{~cm}$ below the water surface and $10-15 \mathrm{~cm}$ above the surface. The dome was positioned on the reservoir surface, and concentrations of the two gases were measured in the chamber headspace during an incubation period of 10 to 15 minutes. During the incubation, the chamber was allowed to float freely and drift with the water current. The chamber was connected to a field Fourier transform infrared (FT-IR) gas analyzer (Gasmet model DX-4015 Multigas Analyzer) in a closed-loop arrangement. In this mode, we recorded the concentrations of $\mathrm{CO}_{2}$ and $\mathrm{CH}_{4}$ at one-minute intervals. We used the slope of the increasing concentrations through time to calculate $\mathrm{CO}_{2}$ and $\mathrm{CH}_{4}$ emissions.

\section{Thin boundary layer flux calculations}

We used the thin boundary layer method to estimate gas fluxes from the reservoir surface in cases where the floating dome method for measuring $\mathrm{CO}_{2}$ and $\mathrm{CH}_{4}$ was not possible, and in several cases where the floating chamber was not operating properly. The thin boundary layer method uses semi-empirical equations to calculate emission from measured concentrations of the gas in the surface water and the gas-exchange coefficient. The thin-boundary method is described in detail in IHA (2010). The flux of gas from water to air (diffusive emissions) was calculated as the product of the gas exchange coefficient for the particular gas in question and the difference between gas concentrations in surface water and air (Equation 1). This approach involves more uncertainty in estimations of GHG emissions and is only used if floating chamber measurements are not possible (Guerin et al. 2007, IHA 2010).

\section{Equations and calculations:}

$$
\text { Flux }=K_{x}\left(\mathrm{C}_{\text {water }}-\mathrm{C}_{\text {air }}\right)
$$

(McIntyre et al. 1995)

where: $\mathrm{C}_{\text {air }}$ is the concentration of gas in the air $1 \mathrm{~m}$ above reservoir surface

$\mathrm{C}_{\text {water }}$ is the concentration of gas in the surface water of the reservoir (obtained by: pGas $* \mathrm{~K}_{0}$ ).

where: pGas is the gas partial pressure

$\mathrm{K}_{0}$ is the gas solubility at a given temperature

$\mathrm{C}_{\mathrm{water}}(\mu \mathrm{mole} / \mathrm{L})=\mathrm{K}_{0}(\mathrm{~mole} / \mathrm{L} / \mathrm{atm}) * \mathrm{pGas}(\mu \mathrm{atm})$

(Morel 1982; Anderson 1982)

For $\mathrm{CO}_{2}: \ln \mathrm{K}_{0}=-58.0931+90.5069 *\left(100 / \mathrm{T}_{\mathrm{k}}\right)+22.294 * \ln \left(\mathrm{T}_{\mathrm{k}} / 100\right)+\mathrm{s} *(0.027766-0.025888 *$

$\left.\left(\mathrm{T}_{\mathrm{k}} / 100\right)+0.0050578 *\left(\mathrm{~T}_{\mathrm{k}} / 100\right)^{2}\right)$

(Weiss 1974)

where: $T_{k}$ is the temperature in Kelvin

$\mathrm{s}$ is salinity of the water (in parts per thousand)

$\mathrm{K}_{0}$ is expressed as the solubility of $\mathrm{CO}_{2}$ in water in moles/L/atm

For $\mathrm{CH}_{4}: \ln \mathrm{K}_{0}=-115.6477+\left(155.5756 /\left(\mathrm{T}_{\mathrm{k}} / 100\right)\right)+65.2553 * \ln \left(\mathrm{T}_{\mathrm{k}} / 100\right)-6.1698 *\left(\mathrm{~T}_{\mathrm{k}} / 100\right)$

(Lide 2007)

where: $\mathrm{K}_{0}$ is expressed as the solubility of $\mathrm{CH}_{4}$ in water in mole fraction/atm

Multiply $\mathrm{CH}_{4} \mathrm{~K}_{0}$ (mole fraction/atm) by: $1000 \mathrm{~g} / \mathrm{L} / 18.0153 \mathrm{~g} / \mathrm{mole}$ to get $\mathrm{K}_{0}$ expressed as moles/L/atm 
To calculate the TBL:

$\mathrm{k}_{\mathrm{x}}=\mathrm{k}_{600}(\mathrm{Sc} / 600)^{-\mathrm{x}}$

where: $\mathrm{k}_{\mathrm{x}}$ is the gas exchange coefficient expressed in $\mathrm{cm} / \mathrm{h}$

$x=0.66$ for wind speed $\leq 3 \mathrm{~m} / \mathrm{s}$ or $x=0.5$ for wind speed $>3 \mathrm{~m} / \mathrm{s}$

$\mathrm{Sc}=$ the $\mathrm{Schmidt}$ number for the selected gas

$\mathrm{Sc}\left(\mathrm{CO}_{2}\right)=1911.1-118.11 \mathrm{t}+3.4527 \mathrm{t}^{2}-0.04132 \mathrm{t}^{3}$

(Wanninkhof 1992)

$\mathrm{Sc}\left(\mathrm{CH}_{4}\right)=1897.8-114.28 \mathrm{t}+3.2902 \mathrm{t}^{2}-0.039061 \mathrm{t}^{3}$

(Wanninkhof 1992)

where $\mathrm{t}=$ temperature in Celsius

$\mathrm{K}_{600}=2.07+\left(0.215 * \mathrm{U}_{10}{ }^{1.7}\right)$

(Cole and Caraco 1998)

where: $\mathrm{K}_{600}$ is the gas exchange coefficient expressed in $\mathrm{cm} / \mathrm{h}$

$\mathrm{U}_{10}=1.22 * \mathrm{U}_{1}$

$\mathrm{U}_{1}=$ wind speed $(\mathrm{m} / \mathrm{s})$ at the water surface, $\mathrm{U}_{10}=$ frictionless wind speed $(\mathrm{m} / \mathrm{s})$ at $10 \mathrm{~m}$

(Crusius and Wanninkhof 2003)

To obtain flux expressed as $\mathrm{mg}$ gas $/ \mathrm{m}^{2} /$ day:

$\left(1 \mathrm{~L} / 1000 \mathrm{~cm}^{3} * 24 \mathrm{~h} / 1\right.$ day $* 10000 \mathrm{~cm}^{2} / \mathrm{m}^{2} * 1 \mathrm{mmole} / 1000 \mu$ mole $) *$ molecular weight of gas

\section{Ebullition measurements of $\mathrm{CO}_{2}$ and $\mathrm{CH}_{4}$}

Rates of $\mathrm{CO}_{2}$ and $\mathrm{CH}_{4}$ emission by ebullition were measured at a subset of the sites where diffusive fluxes were measured. Where the water depth is $<10 \mathrm{~m}$ and during periods when $\mathrm{CH}_{4}$ concentrations in bottom waters are high, bubble emissions can be significant for $\mathrm{CH}_{4}$, but bubble emissions are typically less important for $\mathrm{CO}_{2}$ and $\mathrm{N}_{2} \mathrm{O}$ (IHA 2010). To measure ebullition, inverted funnel collectors (surface area $1 \mathrm{~m}^{2}$ ) were deployed over a 24-h period. Gas was collected in a syringe mounted on top of the funnel. The volume of gas ( $\mathrm{ml}$ ) collected from each funnel was recorded and injected into a pre-evacuated glass serum vial sealed with a butyl stopper, and the vials were stored inverted in a water-filled 50-ml centrifuge tube until analysis by GC (see below for detailed GC methods). Bubble emissions were calculated from the measured GHG concentrations multiplied by the volume of gas collected, divided by the product of the area of the funnel collectors and the duration of the deployment.

\section{Tailwater emissions of $\mathrm{CO}_{2}$ and $\mathrm{CH}_{4}$}

To estimate the change in net carbon emissions attributable to converting the river into a reservoir, we needed to account for emissions of $\mathrm{CO}_{2}$ and $\mathrm{CH}_{4}$ from the reservoir and its tailwaters. We used a mass balance approach to estimate GHG emissions from the tailwaters. We determined the concentrations of dissolved GHG at four tailwater sites located at increasing distances from the dam, on multiple sampling dates (Figure 1). Subsamples of water samples for this purpose $(7 \mathrm{ml}$ each) were collected from the sites with a van Dorn water sampler during the monthly visits, when hydropower was being generated. The concentrations of the gases in these samples were determined by GC headspace analysis as reported above. 
We calculated emissions from concentrations of the dissolved gases based on the assumption that the loss in dissolved $\mathrm{CO}_{2}$ and $\mathrm{CH}_{4}$ between $\mathrm{T} 1$ and $\mathrm{T} 4$ was due exclusively to emissions (i.e., uptake of $\mathrm{CO}_{2}$ by algae was considered insignificant as a loss factor, as was the conversion of $\mathrm{CH}_{4}$ to $\mathrm{CO}_{2}$ by microbes). The losses in concentration ( $\mu$ moles per liter) were multiplied by mean daily discharge (liters per day), then divided by the surface area of the tailwater reach (6440 $\mathrm{m}$ in length $\mathrm{x}$ an average of $130 \mathrm{~m}$ in width), before being converted to $\mathrm{mg}$ (multiplying by 44.01 $\mathrm{mg} / \mathrm{mole}$ in the case of $\mathrm{CO}_{2}$, or by 16.04 in the case of $\mathrm{CH}_{4}$ ) per square meter per day.

\section{Pre-impoundment river emissions}

Net GHG emissions from a reservoir require an estimate of emissions from the river before it was impounded. We estimated pre-impoundment river emissions using the measurements of emissions from free-flowing regions of the three major tributary rivers to the reservoir. These river emission rates were determined using the thin boundary layer method (see Guerin et al. 2007, IHA 2010), due to boat access limitations and because the relatively high water velocities prevented use of the floating chamber.

For the three tributary rivers, we had 23 observations in total ( 8 each for the French Broad River and the Pigeon River, and 7 for Nolichucky River). The before-dam emission rate for the preimpounded river was then estimated by multiplying the mean emissions rate for the three tributary rivers $\left(9.88 \mathrm{~g} / \mathrm{m}^{2} /\right.$ day $)$ by the pre-dam river's width $(95 \mathrm{~m})$ and length $(61.56 \mathrm{~km})$, and adding to that value, the mean emissions for the influent rivers multiplied by the area represented now by the tailwater segment (historical width, $95 \mathrm{~m}$; length, $6.44 \mathrm{~km}$ ). To estimate net change (i.e., comparison of pre- and post-impoundment conditions), we expressed the emissions results on an annual basis; this necessitated pooling data across sites in the reservoir, and summing emissions over months so as to account for areal differences related to stage height.

\section{Headspace GHG analysis by gas chromatography}

To determine the concentrations of dissolved GHG in the field water samples, we withdrew $7 \mathrm{ml}$ of freshly collected water from the van Dorn sampler with a 10-ml syringe, taking care not to introduce air into the sample. The 7-ml sample was then injected into a pre-evacuated, sealed glass vial containing $0.4 \mathrm{~g} \mathrm{KCl}$ as a preservative. These vials were stored inverted in 50-ml centrifuge tubes containing water. In the laboratory, we added $6 \mathrm{ml}$ of $\mathrm{He}$ to each vial (bringing the contents of the vials to atmospheric pressure), and the vials were returned to the water-filled centrifuge tubes and kept refrigerated until analysis (within one month). Just before analysis, the vials were brought to room temperature and placed on a shaker table for $\sim 3$ minutes to ensure equilibration of water and headspace gases in the vial. A 150- $\mu$ l sample of the headspace gas was then analyzed for $\mathrm{CO}_{2}$ and $\mathrm{CH}_{4}$ concentrations. We used an Agilent $6850 \mathrm{GC}-\mathrm{TCD}$ (GC equipped with a thermoconductivity detector and 30-m x 0.32-mm x 0.10- $\mu \mathrm{m}$ film PLOT-U capillary column; J\&W Scientific) for measuring $\mathrm{CO}_{2}$ and $\mathrm{N}_{2} \mathrm{O}$, and an Agilent 6890 GC-FID (GC equipped with a flame ionization detector and $30 \mathrm{~m}$ x $0.32 \mathrm{~mm}$ x $0.5 \mu \mathrm{m}$ film DB-FFAP capillary column; J\&W Scientific) for measurements of $\mathrm{CH}_{4}$. 
We calculated the concentrations of the GHG in the original water sample from the measured amounts of $\mathrm{CO}_{2}$ and $\mathrm{CH}_{4}$ based on the partitioning between the water and headspace gas in the sample vial as described in IHA (2010).

The diffusive emission rates for each gas were calculated based on the rate of increase in GHG concentrations in the floating chamber over time, multiplied by the chamber headspace volume, divided by the surface area of the chamber. If GHG concentrations in the chamber deviated from a linear increase during the incubation period, we used only the initial linear rate of increase to calculate emission rate (Mosher et al. in review).

\section{Ancillary measurements}

Other measurements were made at the sites on each sampling date to help interpret the GHG emission rates and for potential use in predictive models of GHG emissions. These measurements included: air temperature and wind speed; vertical profiles of water temperature, specific conductance, $\mathrm{pH}$, dissolved oxygen concentration, and chlorophyll concentration. The data for the vertical profiles were obtained at 1 - to 2 -m depth intervals using a water quality sonde (YSI model $6820 \mathrm{~V} 2$ ).

Water samples also were collected from two depths (0.5-1 $\mathrm{m}$, and 1-2 $\mathrm{m}$ above the bottom) for measuring dissolved organic carbon (DOC) concentrations with a Shimadzu TNM-1 hightemperature combustion analyzer. These water samples also were analyzed for selected nutrient concentrations $\left(\mathrm{NH}_{4}, \mathrm{NO}_{3}{ }^{-}\right.$, total soluble $\mathrm{N}$, total $\mathrm{N}$, soluble reactive $\mathrm{P}$, total soluble $\mathrm{P}$, and total $\mathrm{P}$ ) using an autoanalyzer (Seal Analytical Model AA3) and standard wet chemistry methods (American Public Health Association, APHA 1992). Samples for DOC, $\mathrm{NH}_{4}, \mathrm{NO}_{3}{ }^{-}$, total soluble $\mathrm{N}$, soluble reactive $\mathrm{P}$, and total soluble $\mathrm{P}$ were filtered in the field (Whatman GFF filters) and placed on ice. In the laboratory, DOC samples were acidified and refrigerated until analysis (within two months). All other nutrient samples were frozen until analysis (within four months). Bottom samples for determining sediment organic matter content were collected once from each reservoir site using a benthic sampler (e.g., an Eckmann dredge or a Ponar sampler).

Data relating reservoir water surface area to pool stage (water level) were acquired to estimate variation in reservoir surface area over the year of measurement (personal communication, Boualem Hadjerioua, Environmental Sciences Division, Oak Ridge National Laboratory). Width and length of the original river impounded by the reservoir were estimated using available morphometry data. These data were used to estimate the surface area of the pre-impoundment river, and to estimate the increase in water surface area due to differences in the reservoir operation over an annual period.

On each sampling date, a 1.5-L van Dorn water sampler was used to collect water samples from the five main-channel and five cove sites for $\mathrm{CO}_{2}$ and $\mathrm{CH}_{4}$ concentrations at four depths in the water column (two from the epilimnion and two from the hypolimnion).

In the attempt to determine factors that influenced or controlled GHG emissions from Douglas Lake, we used the ancillary measurements (i.e., water temperature, dissolved oxygen, dissolved $\mathrm{CO}_{2}$ and $\mathrm{CH} 4$, nitrate, ammonia, total phosphorus, soluble reactive phosphorus, dissolved organic 
carbon etc) and explored relationships between GHG emission and these other measured factors using several statistical techniques, including stepwise multiple regression, one- and two-way analysis of variance, and canonical correspondence analysis.

\section{Preliminary estimate of net emissions of GHG from Douglas Lake}

To prepare a preliminary estimate of the net emissions of GHG from Douglas Lake, we had to consider emissions from the river before the reservoir was created, the change in emissions of the forested land that was inundated by creating the reservoir, and the emissions from the reservoir and its tailwaters after the lake had been created. This necessitated considering (a) the loss of riparian area due to flooding in 1943, (b) $\mathrm{CO}_{2}$ and $\mathrm{CH}_{4}$ diffusive emissions from the "historical river", (c) diffusive emissions of GHG from the ten sites we sampled within the reservoir, and (d) losses of dissolved $\mathrm{CO}_{2}$ and $\mathrm{CH}_{4}$ over the tailwater reach. Since ebullition was minor $(<0.1 \%$ of diffusive emissions for $\mathrm{CO}_{2}$ and $<1 \%$ for $\mathrm{CH}_{4}$ ), our estimates for net emissions ignores ebullition. The rationale for the approach and calculations we used to estimate the changes in emissions caused by creating the reservoir necessitated certain assumptions, as described below.

a. First, we estimated carbon emissions from the French Broad River, before it was impounded to create Douglas Lake. The area of the "historical river" of interest for this estimate was calculated by multiplying the length of the present reservoir (about 61,560 $\mathrm{m}$ ) by the river's mean width (estimated at $95 \mathrm{~m}$ ). We then calculated the mean effusive emissions data from the sampling sites in the three tributary rivers used in this study (the French Broad, Nolichucky and Pigeon Rivers; Fig. 1), and converted these emissions rates (mg/day) to annual emissions rates (365 days per year). We then multiplied the surface area of the historical river segment by the annual areal emissions rates to prepare our best guess of the GHG emissions from the "historical river".

b. When the river was dammed in 1943, the rising waters flooded an area of land. We presumed that, before flooding, the land was forested, and that this forested area behaved ecologically as a net carbon sink. We presumed that the area of flooded land was equal to the mean surface area of Douglas Lake, minus the area of the river that "became" the reservoirs (see (a), above). Our estimate for area flooded was based on the annual average area of the reservoir, which varied through time due to hydropower operations (Bo Hadjerioua, personal communication).

c. Emissions of GHG from Douglas Lake were measured at about monthly intervals at ten within-reservoir sampling sites. Using these data, we calculated emission rates on an areal basis, adjusting the area for each sampling event based on the mean area of the reservoir for each month. We then summing the monthly emissions results (accounting for differences in the number of days per month) to provide the annual estimated emissions value.

d. To estimate releases of GHG from the tailwater reach, we calculated reach length $(6.44$ $\mathrm{km})$ and reach average width $(130 \mathrm{~m})$, then considered measured concentrations of dissolved gases, at T1 and T4; calculated the mean change (T4-T1), assuming all "lost" gas left as emissions. 
We summarized the net emissions data developed by considering (a) through (d), above, in tabular form. 


\section{RESULTS AND DISCUSSION}

\section{Diffusive emissions of $\mathrm{CO}_{2}$ and $\mathrm{CH}_{4}$ - reservoir overall}

Using emissions data from the three upstream river tributaries, we estimated the previous net diffusive emission of $\mathrm{CO}_{2}$ from the free-running river (i.e., French Broad segment before impoundment) to be about $2.11 \times 10^{7} \mathrm{~kg}$ per year. In 2010, the net diffusive emission of $\mathrm{CO}_{2}$ from Douglas Lake (including tailwaters) was about $1.11 \times 10^{8} \mathrm{~kg}$ per year. Impounding the river to create Douglas Lake increased water surface area by about 15.3 -fold (from $\sim 5.85 \times 10^{6} \mathrm{~m}^{2}$ to $\sim 8.92 \times 10^{7} \mathrm{~m}^{2}$ ). Thus, on an absolute basis, the amount of $\mathrm{CO}_{2}$ released from the impoundment, compared to the previous free-running river segment, has increased by a factor of about 5.3. However, expressed on a per-unit area basis, the reservoir emissions of $\mathrm{CO}_{2}$ in 2010 were lower than those of the free-running river by about a factor of $\sim 2.9$ (Table 1 ).

Table 1. Net diffusive emissions of $\mathrm{CO}_{2}$ and $\mathrm{CH}_{4}$ from Douglas Lake and its tailwaters, and from the free-flowing French Broad River (the latter representing conditions before the river was impounded to create Douglas Lake).

\begin{tabular}{|c|c|c|c|c|c|c|}
\hline & \multicolumn{2}{|c|}{ Douglas Lake } & \multicolumn{2}{|c|}{$\begin{array}{l}\text { Reservoir tailwater } \\
\text { reach }\end{array}$} & \multicolumn{2}{|c|}{$\begin{array}{c}\text { Free-running French } \\
\text { Broad River* }\end{array}$} \\
\hline & $\mathrm{CO}_{2}$ & $\mathrm{CH}_{4}$ & $\mathrm{CO}_{2}$ & $\mathrm{CH}_{4}$ & $\mathrm{CO}_{2}$ & $\mathrm{CH}_{4}$ \\
\hline total $\mathrm{kg} /$ year & $7.91 \times 10^{7}$ & $2.98 \times 10^{5}$ & $3.22 \times 10^{7}$ & $2.80 \times 10^{2}$ & $2.11 \times 10^{7}$ & $5.83 \times 10^{2}$ \\
\hline $\mathrm{mg} / \mathrm{m}^{2} /$ year & $1.25 \times 10^{6}$ & $3.74 \times 10^{3}$ & $3.85 \times 10^{7}$ & $3.35 \times 10^{2}$ & $3.61 \times 10^{6}$ & $9.98 \times 10^{1}$ \\
\hline
\end{tabular}

*Estimated as the average of three upstream tributary rivers to Douglas Lake $(\mathrm{N}=19)$.

The net diffusive emissions of $\mathrm{CH}_{4}$ were much lower than those of $\mathrm{CO}_{2}$, for all sampling sites and dates (cf. Table 1). The amounts of $\mathrm{CH}_{4}$ released were $<<0.1 \%$ of the $\mathrm{CO}_{2}$ emissions for the freerunning tributaries and the reservoir tailwaters. For the ten within-reservoir sampling sites, $\mathrm{CH}_{4}$ emissions were on average only about $0.34 \%$ as great as the $\mathrm{CO}_{2}$ emissions on a molar basis. The relative importance of $\mathrm{CH}_{4}$ versus $\mathrm{CO}_{2}$ in this study is similar to that reported by others $(0.41 \%$, for boreal zone systems (Ojala et al. 2011). Even adjusting for global warming potential, $\mathrm{CH}_{4}$ emissions from Douglas Lake seem unlikely to exceed $\sim 8 \%$ of the influence of $\mathrm{CO}_{2}$. Barros et al. (2011) suggest that hydropower reservoir $\mathrm{CO}_{2}$ emissions can exceed $\mathrm{CH}_{4}$ emissions by a factor of about $16 \mathrm{X}$, which also is in reasonably good agreement with our estimate of $\mathrm{CO}_{2}$ and $\mathrm{CH}_{4}$ emissions for Douglas Lake.

\section{Diffusive emissions of $\mathrm{CO}_{2}$ and $\mathrm{CH}_{4}$ - reservoir tailwaters}

The tailwater reach of Douglas Lake, as defined in this study, is relatively short $(6.44 \mathrm{~km})$ compared to the overall length of the reservoir $(\sim 61.56 \mathrm{~km})$. But as others have reported (cf. Guerin et al., 2007), the fluxes of $\mathrm{CO}_{2}$ to the atmosphere by tailwaters can be much greater than 
diffusive emissions of $\mathrm{CO}_{2}$ from the reservoir surface. The tailwaters for Douglas Lake accounted for about $40 \%$ of the total emissions of $\mathrm{CO}_{2}$ for the entire reservoir on an annual basis in 2010 (Table 1).

Ebullition of $\mathrm{CO}_{2}$ from Douglas Lake was much lower than rates of diffusive emissions of $\mathrm{CO}_{2}$, as has been reported by other investigators for other freshwater lakes and reservoirs (cf. Poissant et al. 2007).

Concentrations of $\mathrm{CO}_{2}$ and $\mathrm{CH}_{4}$ dissolved in surface waters of Douglas Lake, and the diffusive emissions of these two gases, were strongly affected by time of year, with diffusive emissions being greater when surface water temperatures were elevated (Table 2).

\section{Factors Influencing Diffusive Emissions of $\mathrm{CO}_{2}$ and $\mathrm{CH}_{4}$ from Douglas Lake}

Multivariate analyses of the full Douglas Lake data set did not provide powerful clues as to factors influencing GHG emissions. However we were able to identify influential factors and sets of conditions by sub-setting the data. Our strategy for sub-setting was simple: from other published studies, we reasoned first that water temperature and water depth were likely to be important determinants of GHG emissions. Water temperature affects microbial respiration and gas diffusion rates, among many other things, and depth should affect methane emissions in particular, because methane is produced largely by sediment-dwelling microbes, and can be converted to $\mathrm{CO}_{2}$ as it diffuses upward into more oxygenated strata. This understanding directed us to conceptually sub-set the data temporally on the basis of warm-water versus cool-water conditions, and spatially on the basis of sites that were shallow versus deep. But we needed a credible method for establishing the criteria for depth (deep versus shallow), and surface-water temperature (warm versus cool).

To identify the temperature "break point" for classifying conditions as cool or warm, we used a series of two-way ANOVAs, with bottom-water transformed $\mathrm{CH}_{4}$ concentration ( $\log$ [CH4]bottom) as the dependent variable. We selected log [CH4]-bottom as the best 
Table 2: Measured parameters for five main channel and five coves sites from Douglas Reservoir.

\begin{tabular}{|c|c|c|c|c|}
\hline & $\begin{array}{l}\text { Shallow, cool } \\
\quad(n=21)\end{array}$ & $\begin{array}{l}\text { Shallow, warm } \\
\qquad(\mathrm{n}=12)\end{array}$ & $\begin{array}{l}\text { Deep, cool } \\
\qquad(\mathrm{n}=23)\end{array}$ & $\begin{array}{l}\text { Deep, warm } \\
\qquad(\mathrm{n}=28)\end{array}$ \\
\hline Depth (m) & $5.58 \pm 0.06$ & $5.97 \pm 0.84$ & $17.44 \pm 1.11$ & $17.15 \pm 1.14$ \\
\hline Surface Temp $\left({ }^{\circ} \mathrm{C}\right)$ & $16.40 \pm 1.48$ & $28.52 \pm 0.41$ & $17.97 \pm 1.32$ & $29.39 \pm 0.38$ \\
\hline Bottom Temp $\left({ }^{\circ} \mathrm{C}\right)$ & $15.70 \pm 1.42$ & $26.83 \pm 0.63$ & $14.11 \pm 1.17$ & $23.18 \pm 0.74$ \\
\hline Diss. $\mathrm{O}_{2}$ Surface $(\mathrm{mg} / \mathrm{L})$ & $10.39 \pm 0.52$ & $7.59 \pm 0.35$ & $10.93 \pm 0.46$ & $8.21 \pm 0.14$ \\
\hline Diss. $\mathrm{O}_{2}$ Bottom (mg/L) & $9.03 \pm 0.63$ & $5.55 \pm 0.60$ & $7.06 \pm 0.70$ & $1.46 \pm 0.37$ \\
\hline$\left[\mathrm{CO}_{2}\right]$ Surface (umole/L) & $150.57 \pm 48.71$ & $306.69 \pm 96.67$ & $180.74 \pm 38.73$ & $86.45 \pm 15.35$ \\
\hline$\left[\mathrm{CO}_{2}\right]$ Bottom (umole/L) & $227.50 \pm 103.04$ & $481.47 \pm 114.22$ & $601.49 \pm 127.46$ & $810.37 \pm 124.95$ \\
\hline$\left[\mathrm{CH}_{4}\right]$ Surface (umole/L) & $0.03 \pm 0.01$ & $0.20 \pm 0.15$ & $0.01 \pm 0.01$ & $0.03 \pm 0.00$ \\
\hline$\left[\mathrm{CH}_{4}\right]$ Bottom (umole/L) & $0.03 \pm 0.01$ & $0.06 \pm 0.01$ & $0.04 \pm 0.03$ & $0.50 \pm 0.15$ \\
\hline
\end{tabular}


indicator for temperature effects because this variable should best reflect metabolic activity related to methanogenesis. We expected that $\mathrm{CH}_{4}$ emissions would be influenced by both $\mathrm{CH}_{4}$ production and by water depth, because produced methane would need to travel through water column to escape to the atmosphere. In the ANOVAs, factor one was maximum water depth (sites having a maximum depth of < $10 \mathrm{~m}$ constituted the shallow class, sites having maximum depths $>10$ meters constituted the deep class), and factor 2 was surface water temperature (warm, or cool). To identify the warm-versus-cool criterion, we ran the ANOVAs multiple times, keeping site-classification by maximum water depth constant but selecting, among the runs, surface-water cut-off values of $18,20,21,22,23,24,25,26$, or $28{ }^{\circ} \mathrm{C}$. We then graphed the outcomes by plotting, on the $\mathrm{Y}$ axis, the $\mathrm{F}$ values (an index of the amount of variance explained) as a measure of the effect of water temperature, and the surface water temperature on the $\mathrm{X}$ axis. The result (Figure 3) clearly suggested that $\mathrm{CH}_{4}$ production "kicked in" between 21 and $22{ }^{\circ} \mathrm{C}$.

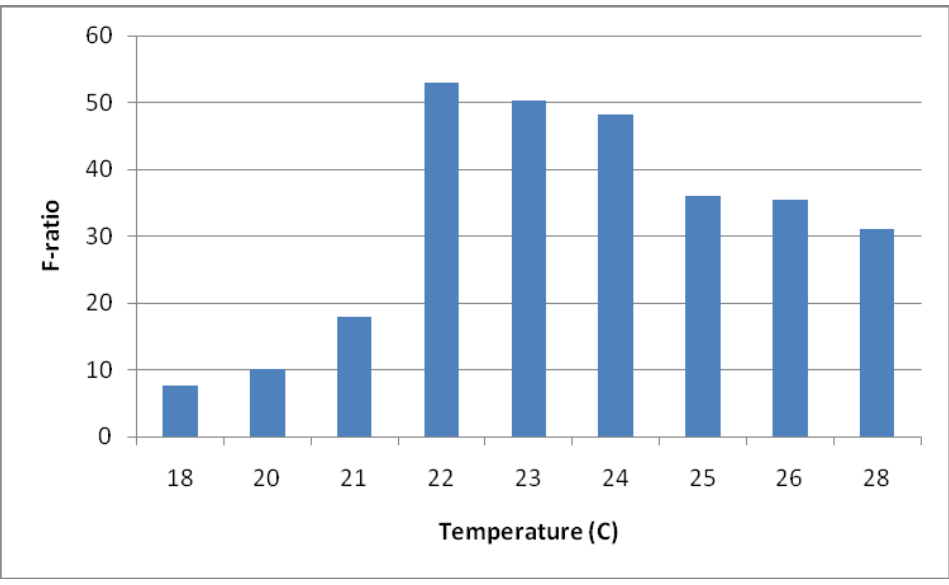

Figure 3: F-ratios plotted for increasing temperatures for $\mathrm{CH}_{4}$ emission rates in Douglas Lake.

Upon establishing the warm-versus-cool criterion at $22{ }^{\circ} \mathrm{C}$, we considered the depth criterion. After reviewing the results of classifying sites by maximum depth for various depth cut-off values, we retained a cut-off for shallow versus deep sites at $10 \mathrm{~m}$ for practical reasons. Hydropower production caused variations in water depth, so several of the cove sites were sometimes deeper than $10 \mathrm{~m}$ and sometimes shallower than $10 \mathrm{~m}$. But setting the criterion at $8 \mathrm{~m}$, for example, strongly reduced the number of observations within the shallow-site class, weakening ability to test statistically for site-depth effects. Similarly, a depth criterion of $15 \mathrm{~m}$ caused some of the "channel" sites to occasionally be classified as shallow ("cove") sites. The 10-m criterion yielded a good balance for numbers of observations per site water-depth class.

Using the warm-cool criterion value of $22{ }^{\circ} \mathrm{C}$ and the deep-shallow criterion of $10 \mathrm{~m}$ to establish classes, we then tested for class effects on diffusive emissions of $\mathrm{CO}_{2}$ and $\mathrm{CH}_{4}$ using 2-way ANOVAs. Under cooler conditions, shallow sites did not release much $\mathrm{CO}_{2}$; under warm-water conditions, the emissions of $\mathrm{CO}_{2}$ from the shallow sites increased more than four-fold. Conversely, $\mathrm{CO}_{2}$ emissions were higher during times when surface water was cooler at deep sites, and the $\mathrm{CO}_{2}$ diffusive emissions declined substantially (by $40 \%$ ) when surface-water temperatures increased (Figure 4). 
The site water-depth versus surface-water temperature pattern for $\mathrm{CH}_{4}$ diffusive emissions was largely the inverse of that for $\mathrm{CO}_{2}$ : $\mathrm{CH}_{4}$ emissions were greater at shallow-water sites during cool-water conditions (Figure 4), but shallow- and deep-water sites were similar with respect to $\mathrm{CH}_{4}$ emissions during warmwater conditions (Figure 4).

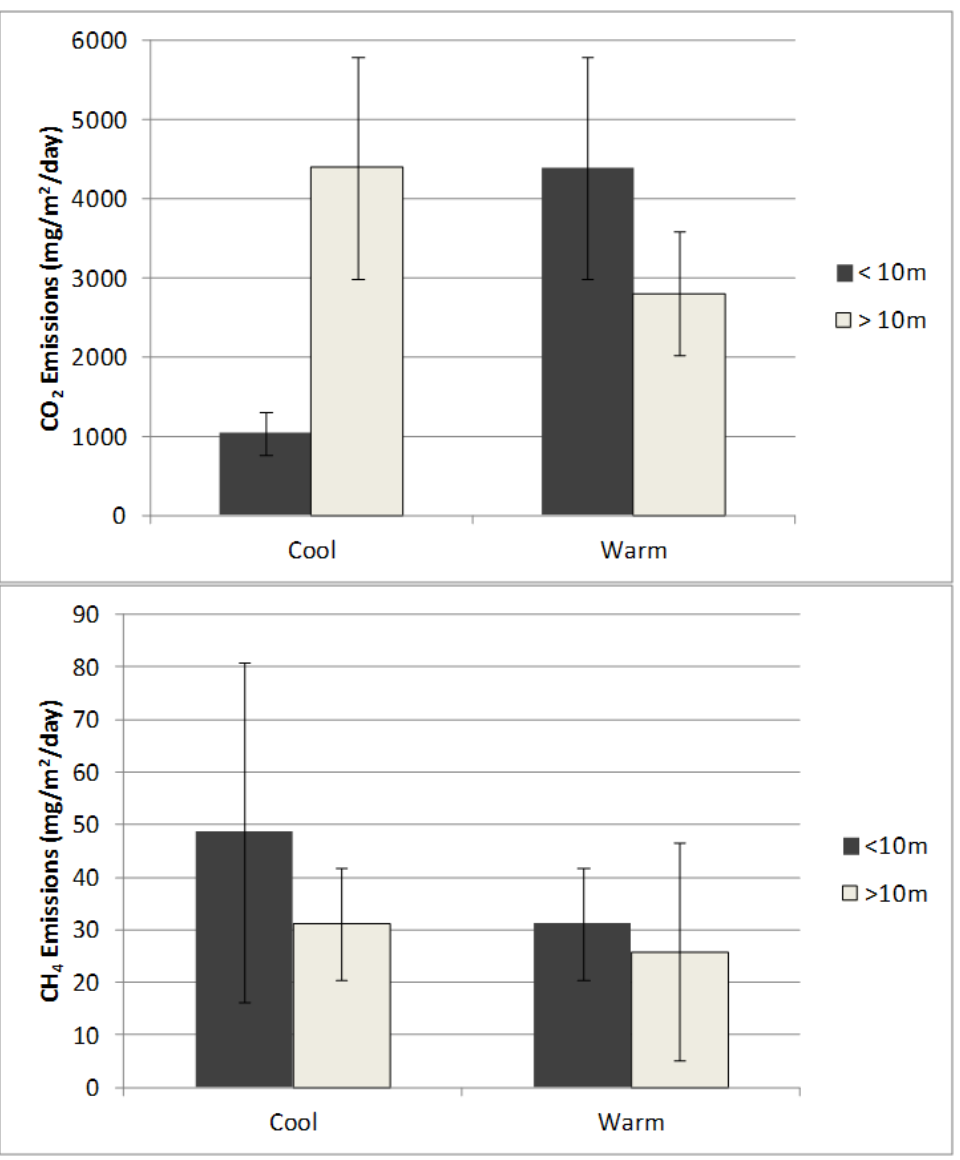

Figure 4. Mean diffusive emissions ( \pm $\mathrm{SE}$ ) of $\mathrm{CO}_{2}$ (upper) and $\mathrm{CH}_{4}$ (lower) from Douglas Lake, from relatively shallow sites $(<10 \mathrm{~m}$ deep) and deep sites $(>10 \mathrm{~m})$, when surface water temperatures of the sites were cool $\left(<22{ }^{\circ} \mathrm{C}\right)$ or warm $\left(>22{ }^{\circ} \mathrm{C}\right)$. 
We also used a series of one-way ANOVAs to search for possible effects of other factors on the diffusive emissions of $\mathrm{CO}_{2}$ and $\mathrm{CH}_{4}$. The factors we explored this way included concentrations of ammonia, dissolved oxygen, dissolved organic carbon, carbon dioxide, and nitrate nitrogen.

We presumed a priori that diffusive emissions of $\mathrm{CO}_{2}$ and $\mathrm{CH}_{4}$ from Douglas Lake would be affected by surface water temperature and site depth. Multivariate analyses did not reveal any strong predictors of either $\mathrm{CO}_{2}$ or $\mathrm{CH}_{4}$ emissions, using statistical methods that were allowed access to the full data set.

When we classified the data on the basis of water temperature and on the basis of maximum water depth, we found several water-quality factors that related statistically to the diffusive emissions of both $\mathrm{CO}_{2}$ and $\mathrm{CH}_{4}$. Among these were surface SRP concentrations and bottom water $\mathrm{NO}_{3}$ concentrations for $\mathrm{CO}_{2}$ emissions, and bottom water $\mathrm{CH}_{4}$ concentrations for $\mathrm{CH}_{4}$ emissions.

Based on the results of a series of one-way ANOVAs, diffusive emissions of $\mathrm{CO}_{2}$ from Douglas Lake were related to some extent to surface water temperature (Table 3) and were greater in warmer seasons than in cooler seasons. The emissions of $\mathrm{CH}_{4}$ were not influenced much by temperature (Table 3). As has been reported in other studies of temperate-region reservoirs, diffusive emissions of $\mathrm{CH}_{4}$ were much lower than those of $\mathrm{CO}_{2}$.

Table 3. Results of two-way ANOVAs for effects of site depth (shallow versus deep) and surface water temperature (cool versus warm) on the diffusive emissions of $\mathrm{CO}_{2}$ and $\mathrm{CH}_{4}$.

\begin{tabular}{|c|c|c|c|c|c|c|}
\hline & & $\begin{array}{c}\text { Sum of } \\
\text { Squares }\end{array}$ & $\begin{array}{c}\text { Degrees of } \\
\text { Freedom }\end{array}$ & MSE & F ratio & P \\
\hline $\mathbf{C O}_{2}$ & Water depth & $2.57 \times 10^{5}$ & 1 & $2.57 \times 10^{5}$ & 0.027 & 0.868 \\
\hline & Water temperature & $9.93 \times 10^{7}$ & 1 & $9.93 \times 10^{7}$ & 10.72 & 0.0016 \\
\hline & Interaction term & $1.74 \times 10^{7}$ & 1 & $1.74 \times 10^{7}$ & 1.880 & 0.174 \\
\hline & Total & $8.59 \times 10^{8}$ & 83 & & & \\
\hline $\mathbf{C H}_{\mathbf{4}}$ & Water depth & $1.42 \times 10^{4}$ & 1 & $1.42 \times 10^{4}$ & 1.531 & 0.219 \\
\hline & Water temperature & $2.66 \times 10^{2}$ & 1 & $2.66 \times 10^{2}$ & 0.028 & 0.866 \\
\hline & Interaction term & $8.30 \times 10^{3}$ & 1 & $8.30 \times 10^{3}$ & 0.891 & 0.348 \\
\hline & Total & $7.68 \times 10^{5}$ & 83 & & & \\
\hline
\end{tabular}


A strong seasonal pattern for $\mathrm{CO}_{2}$ diffusive emissions was evident, with the rates being much higher in warmer months than in cooler months. Additionally, although the patterns of $\mathrm{CO}_{2}$ and $\mathrm{CH}_{4}$ emissions were grossly similar with respect to seasonal trends (Figure 5), emission rates for $\mathrm{CO}_{2}$ were far greater than those for $\mathrm{CH}_{4}$.
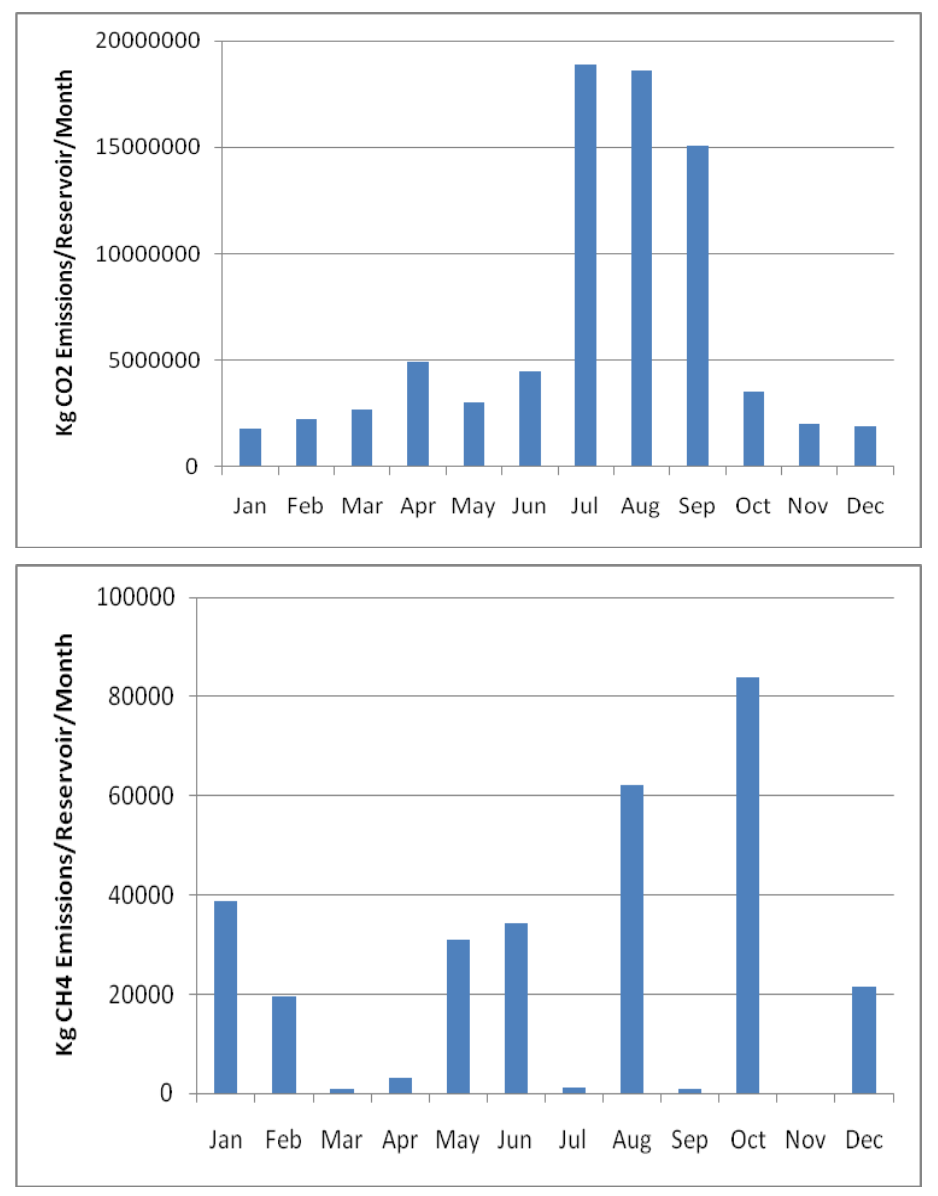

Figure 5a: Monthly estimations of $\mathrm{CO}_{2}$ emissions from the surface of Douglas Reservoir.
Figure 5b: Monthly estimations of $\mathrm{CH}_{4}$ emissions from the surface of Douglas Reservoir.

\section{FY 2011 Sampling Campaign}

The 2011 sampling included three new reservoirs, Allatoona Reservoir in northern Georgia (operated by USACE), and Watts Bar and Cherokee Reservoirs in eastern Tennessee (both operated by TVA). These reservoirs were selected for their differing sizes (surface area and depth), water retention times, forebay hypoxia mitigation strategies and riparian land use. We anticipate reservoir-to-reservoir differences in emissions for both GHGs.

A new Los Gatos Research DLT-100 Greenhouse Gas Analyzer was purchased and used for the FY 2011 sampling. The field portable DLT-100 utilizes cavity ring-down laser absorption spectroscopy and has dual sample introduction ports. Samples may be either injected directly with a syringe in "batch mode" or the analyzer may be connected to the floating dome in "flow mode" allowing for real time collection of greenhouse samples. This analyzer has several advantages over FY2010's methods, including 1) less sample handling error with the direct field injections, 2) excellent durability in the field, and 3) less 
sample processing time. The DLT-100 was first deployed during the April/May sampling campaign and after a few initial "bugs" were worked out, has been operating smoothly.

Allatoona Reservoir, surface area $48.6 \mathrm{~km}^{2}$, is the result of damming of the Etowah River northwest of

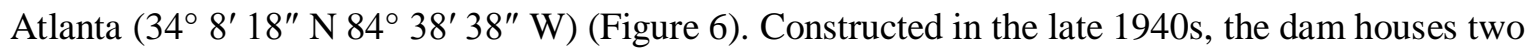
turbine units with a generating capacity of $72 \mathrm{MW}$. Forebay hypoxia mitigation efforts involve altering flows during stratification periods.

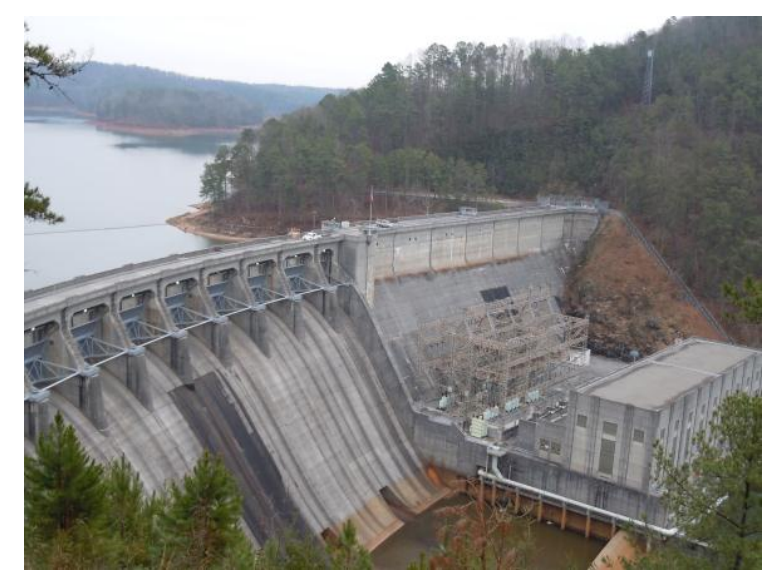

Figure 6: Allatoona Dam and Reservoir, located in northern Georgia, operated by USACE.

Cherokee Dam ( $\left.36^{\circ} 9^{\prime} 58^{\prime \prime} \mathrm{N} 83^{\circ} 29^{\prime} 54^{\prime \prime} \mathrm{W}\right)$ was constructed in 1941 by damming the Holston River. It houses four energy-generating turbines with a $135 \mathrm{MW}$ capacity (Figure 7). The reservoir has an average of $120 \mathrm{~km}^{2}$ surface area and forebay summer hypoxia is mediated by liquid oxygen injections into the bottom waters at the dam.

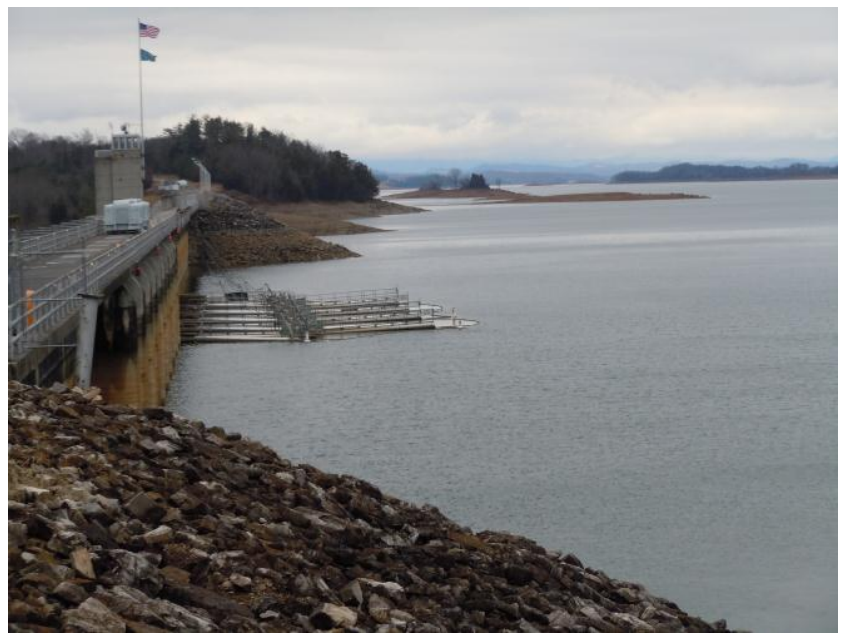

Figure 7: Cherokee Dam and reservoir located in Eastern Tennessee, operated by TVA. 
Watts Bar Dam (35³7' 16.69" N 8446' 53.75" W) was built in 1942, by damming the Tennessee River. It houses five turbines with a generation capacity of $167 \mathrm{MW}$ (Figure 8). The reservoir has an average of $158 \mathrm{~km}^{2}$ surface area and has liquid oxygen injections in the forebay hypolimnion to mitigate summertime hypoxia.

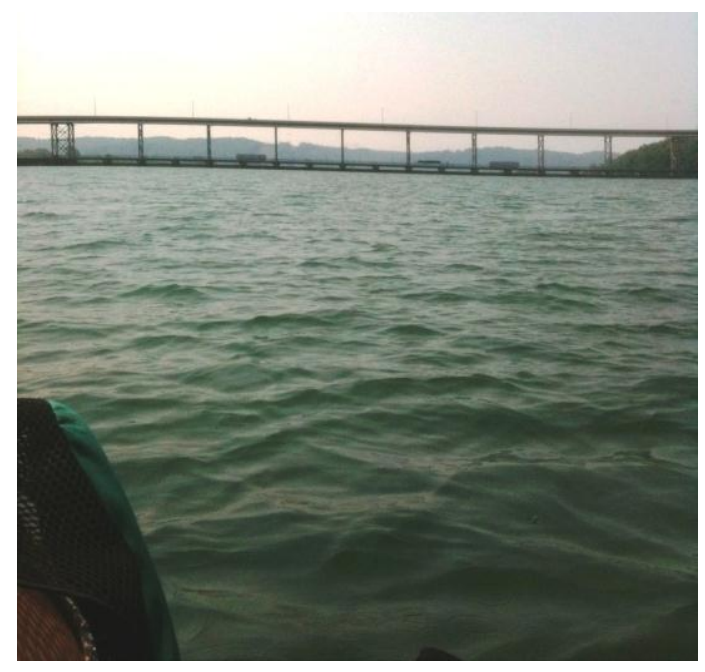

Figure 8: Watts Bar forebay and dam, located in Eastern Tennessee.

All three reservoirs were sampled in March 2011, late April/early May, late June/early July and late August/early September and will be sampled in October/November 2011. A similar strategy was incorporated in FY 2010 sampling: ten reservoir sites (5 cove and 5 main channel) were sampled to measure 1) emissions of $\mathrm{CO}_{2}$ and $\mathrm{CH}_{4}$ from the reservoir surface, 2) vertical gradients of dissolved $\mathrm{CO}_{2}$ and $\mathrm{CH}_{4}$ in the water column, and 3) ebullition fluxes from the reservoir, by inverted funnels suspended below the water surface.

Samples also are being collected before and after the dam as water passes through spillways and turbines to measure gases passing through the dam and being released to the atmosphere. Net emissions are estimated from measurements of greenhouse gas emissions from 2-3 unimpounded sections of tributary rivers to each reservoir.

\section{Other Areas of Project Progress}

1. Two-day training session for PNNL GHG project personnel. Main points covered during the visit were (a) review of site-selection criteria, (b) demonstration of sampling methods, (c) walkthrough tours and explanations of laboratory procedures (GHG analyses by GC and Los Gatos, nutrient analyses), and (d) discussion of programmatic plans and future research avenues.

2. Jennifer Mosher presented a talk titled "Seasonal Greenhouse Gas Emissions from a Temperate U.S. Hydropower Reservoir” authored by Jennifer J. Mosher, Patrick J. Mulholland, Arthur J. Stewart, Allison M. Fortner, Jana R. Phillips and Mark S. Bevelhimer as a session panelist at Hydrovision 2011 Conference in Sacramento, CA in July. 
3. A manuscript from the sampling of Douglas Reservoir is in the final stages of preparation and will be submitted to a peer-reviewed journal by 15 October 2011 . 


\section{FY12 WORKPLAN}

In the first quarter of FY12, we expect to complete field sampling in the three 2011 reservoirs and complete laboratory analysis of all collected water and gas samples. In the spring of 2012, we will begin a third year of sampling that will include a mixture of old and new reservoirs. This will allow us to begin characterizing both inter-annual variability and among-reservoir variability in GHG emissions. In summer of 2012, we will complete a one-time, large-scale synoptic sampling campaign of up to seven hydropower reservoirs in the Southeast. The purpose of this campaign would be to determine the spatial variation of GHG emissions near mid-July, when emission rates should be greatest. Each reservoir would be sampled for ebullition by funnel collectors (three positioned in deep-water sites and three in shallow-water sites); the floating-dome method would be used to measure diffusive emissions at each of these sites, and depthprofile data would be obtained from each site for properties such as water temperature, $\mathrm{pH}$, dissolved oxygen, chlorophyll, oxidation-reduction potential, and conductivity. Relationships between GHG emissions and reservoir characteristics would involve factors noted above and others, and would also include factors that can be determined from hydropower operations or maps, such as reservoir residence time, water surface-area-to-volume ratio, etc. We will analyze results of the synoptic-survey campaign, and then prepare and submit to a peer-reviewed journal a technical manuscript summarizing the results. We anticipate completing a good-quality draft of the manuscript by mid-September, 2012.

To collect data at the peak time of emissions, we need to sample in late July, August, or September. Doing such would not allow time for a thorough analysis of the data by the end of Q4 FY12. We are therefore seeking approval to complete our field sampling by end of FY12, but continue our analysis and preparation of the final report into the Q1 FY13. Our quarterly milestone and deliverables described in the table above reflect this. We expect to do this with money carried over from FY12. 
[THIS PAGE LEFT BLANK INTENTIONALLY] 


\section{REFERENCES}

Anderson, C.B. 2002. Understanding carbonate equilibria by measuring alkalinity in experimental and natural systems. Journal of Geoscience Education. 50:389-403.

Barros, N., J.J. Cole, L.J. Tranvik, Y.T. Prairie, D. Bastviken, V.L.M. Huszar, P. de Giorgio and F. Roland. 2011. Carbon emission from hydroelectric reservoirs linked to reservoir age and latitude. Nature Geoscience 4:593-596.

Cole, J.J. and N.F. Caraco. 1998. Atmospheric exchange of carbon dioxide in a low-wind oligotrophic lake measured by the addition of SF6. Limnology and Oceanography. 43:647-656.

Crusius, J. and R. Wanninkhof. 2003. Gas transfer velocities measured at low wind speed over a lake. Limnology and Oceanography. 48:1010-1017

Galy-Lacaux C, Delmas R, Kouadio G, Richard S, Gosse P. 1999. Long-term greenhouse gas emissions from hydroelectric reservoirs in tropical forest regions. Global Biogeochemical Cycles 13(2):503-517.

Guerin, F., G.Abril, D. Serca, C. Delon, S. Richard, R. Delmas, A. Tremblay and L. Varfalvy. 2007. Gas transfer velocities of $\mathrm{CO} 2$ and $\mathrm{CH} 4$ in a tropical reservoir and its river downstream. Journal of Marine Systems. 66:161-172.

International Hydropower Association (IHA).2010. GHG Measurement Guidelines for Freshwater Reservoirs, The International Hydropower Association, London, UK.

Lide, D.R. 2007. CRC Handbook of Chemistry and Physics, 88th edition. CRC Press, New York.

McIntyre, S., R. Wanninkhof and J.P. Chanton. 1995. Trace gas exchange across the air-water interface in freshwater and coastal marine environments. Chapter 3, p. 52 - 97. In Freshwater and coastal marine environments. P.A. Matson \& Harriss (eds). Blackwell science. 394 p.

Morel, F.M.M. 1982. Principles of aquatic chemistry. John Wiley \& Sons, New York, 446 p.

Mosher, J.J., T.J. Phelps, M.M. Drake, Z.K. Yang, J.H. Campbell, J.G. Moberly, C.W. Schadt, M. Podar, S.D. Brown, T.C. Hazen, A.P. Arkin, A.V. Palumbo, B.A. Faybishenko and D.A. Elias. In review. Microbial community dynamics during in-vitro continuous flow lactate stimulation of chromium and uranium contaminated groundwater. ISME Journal.

Wanninkhof, R., 1992. Relationship between Wind Speed and Gas Exchange Over the Ocean. Journal of Geophysical Research. 97:7373-7382.

Weiss, R.F. 1974. Carbon dioxide in water and seawater: the solubility of a non-ideal gas. Marine Chemistry. 2:203-215. 